\title{
Article
}

\section{Pt-richcore/Sn-richsubsurface/Ptskin nanocubes as highly active and stable electrocatalysts for the ethanol oxidation reaction}

Rubén Rizo, Rosa Arán-Ais, Elliot Padgett, David Muller, María Jesús Lázaro, Jose Solla-Gullon, Juan M. Feliu, Elena Pastor, and Héctor D. Abruña

J. Am. Chem. Soc., Just Accepted Manuscript • DOI: 10.1021/jacs.8b00588 • Publication Date (Web): 23 Feb 2018

Downloaded from http://pubs.acs.org on February 26, 2018

\section{Just Accepted}

"Just Accepted" manuscripts have been peer-reviewed and accepted for publication. They are posted online prior to technical editing, formatting for publication and author proofing. The American Chemical Society provides "Just Accepted" as a service to the research community to expedite the dissemination of scientific material as soon as possible after acceptance. "Just Accepted" manuscripts appear in full in PDF format accompanied by an HTML abstract. "Just Accepted" manuscripts have been fully peer reviewed, but should not be considered the official version of record. They are citable by the Digital Object Identifier (DOI®). "Just Accepted" is an optional service offered to authors. Therefore, the "Just Accepted" Web site may not include all articles that will be published in the journal. After a manuscript is technically edited and formatted, it will be removed from the "Just Accepted" Web site and published as an ASAP article. Note that technical editing may introduce minor changes to the manuscript text and/or graphics which could affect content, and all legal disclaimers and ethical guidelines that apply to the journal pertain. ACS cannot be held responsible for errors or consequences arising from the use of information contained in these "Just Accepted" manuscripts. 


\title{
$\mathbf{P t}_{\text {-rich }}$ core $/$ Sn-rich subsurface $/ \mathbf{P t}_{\text {skin }}$ nanocubes as highly active and stable electrocatalysts for the ethanol oxidation reaction
}

\author{
Rubén Rizo ${ }^{1 *}$, Rosa M. Arán-Ais ${ }^{2}$, Elliot Padgett ${ }^{4}$, David A. Muller ${ }^{4}, \mathrm{M}^{\mathrm{a}}$ Jesús Lázaro $^{5}$, José \\ Solla-Gullón ${ }^{2}$, Juan M. Feliu ${ }^{2}$, Elena Pastor $^{1}$, Héctor D. Abruña ${ }^{3 *}$ \\ ${ }^{1}$ Departamento de Química Física, Instituto de Materiales y Nanotecnología, Universidad de \\ La Laguna, Apdo. 456,38206, La Laguna, Santa Cruz de Tenerife, Spain \\ ${ }^{2}$ Instituto de Electroquímica, Universidad de Alicante, Apartado 99, 03080 Alicante, Spain \\ ${ }^{3}$ Department of Chemistry and Chemical Biology, Baker Laboratory, Cornell University, \\ Ithaca, New York 14853, USA \\ ${ }^{4}$ School of Applied and Engineering Physics, Cornell University, Ithaca, New York 14853, \\ USA \\ ${ }^{5}$ Instituto de Carboquímica, CSIC, Miguel Luesma Castán 4, 50018, Zaragoza, Spain
}

Corresponding author: hda1@cornell.edu

\section{rizo@ffhi-berlin.mpg.de}

\begin{abstract}
Direct ethanol fuel cells (DEFC) are one of the most promising electrochemical energy conversion devices for portable, mobile and stationary power applications. However, more efficient and stable and less expensive electrocatalysts are still required. Interestingly, the electrochemical performance of the electrocatalysts towards the ethanol oxidation reaction (EOR) can be remarkably enhanced by exploiting the benefits of structural and compositional sensitivity and control. Here we describe the synthesis, characterization and electrochemical behaviour of cubic Pt-Sn nanoparticles. The electrochemical activity of the cubic Pt-Sn nanoparticles was found to be about three times higher than that obtained with unshaped Pt-Sn nanoparticles and six times higher than that of Pt nanocubes. In addition, stability tests indicated the electrocatalyst preserves its morphology and remains well-dispersed on the carbon support after 5,000 potential cycles, while a cubic (pure) Pt catalyst exhibited severe agglomeration of the
\end{abstract}


nanoparticles after a similar stability testing protocol. A detailed analysis of the elemental distribution in the nanoparticles by STEM-EELS indicated that Sn dissolves from the outer part of the shell after potential cycling, forming a $\sim 0.5 \mathrm{~nm}$ Pt skin. This particular atomic composition profile having a Pt-rich core, a Sn-rich subsurface layer and a Pt-skin surface structure is responsible of the high activity and stability.

\section{Keywords: Pt-Sn nanocubes, core-shells, EELS-mapping, ethanol oxidation reaction, stability test}

\section{Introduction}

Electrochemical energy conversion and storage play essential roles in addressing the global energy challenge. In particular, direct ethanol fuel cells (DEFC) represent an attractive alternative to resources based on fossil fuel combustion for portable power generation. Ethanol is an eco-friendly and renewable fuel (naturally available in large quantities from biomass), and its complete oxidation to $\mathrm{CO}_{2}$ and $\mathrm{H}_{2} \mathrm{O}$ (with $12 \mathrm{e}^{-}$exchanged in the desired electrocatalytic process) would lead to high energy densities. In addition, the easy handling, storage and transportation of a liquid fuel, such as ethanol, avoids some of the problems associated with gaseous fuel (e.g. $\left.\mathrm{H}_{2}\right)$ systems $^{1,2}$. Over the past decades, platinum $(\mathrm{Pt})$ has been shown to be the most active pure metal catalyst for the ethanol oxidation reaction (EOR). However, Pt is prone to deactivation by the adsorption of some intermediates (such as $\mathrm{CO})$ and reaction by-products during the different pathways of the reaction ${ }^{3-5}$. This fact, in combination with the high cost of $\mathrm{Pt}$, has fueled the search for more active and stable EOR electrocatalysts. To achieve this objective, the synthesis of nanoparticle catalysts (with high surface area to volume ratios), the combination of $\mathrm{Pt}$ with other metals such as $\mathrm{Ru}^{6,7}, \mathrm{Sn}^{8-11}$, $\mathrm{Rh}^{11,12}, \mathrm{Ni}^{12,13}$ or $\mathrm{Au}^{14,15}$, and the control of the exposed Pt surface structure ${ }^{16-22}$, have been 
extensively studied individually. However, the deliberate and integrated combination of these three approaches is clearly complex.

Over the past years, while shape-controlled Pt-M (M = Ni, Co, Fe, Cu, Sn, Ir) nanoparticles ${ }^{23-}$ ${ }^{38}$ have been extensively studied for the oxygen reduction reaction (ORR) $)^{24,25,28-31,33,35-37}$ and the methanol oxidation reaction $(\mathrm{MOR})^{27,33,38}$, studies dealing with the EOR on shapecontrolled Pt and Pt-based catalysts are rather scarce ${ }^{39-42}$. Although Pt-Sn is the most active bimetallic electrocatalyst investigated so far for the $\mathrm{EOR}^{8-11,20,22}$ and shows highly facetsensitive activity, the study of shaped controlled Pt-Sn nanoparticles towards the EOR has not yet been reported. Herein we report the first synthesis of Pt-Sn cubic core-shell nanoparticles, using a previously described method ${ }^{23}$, with greatly enhanced activity towards the EOR. These nanoparticles not only exhibit higher EOR catalytic performance than current polyoriented Pt-Sn nanocatalysts ${ }^{8}$, but also enhanced durability under potential cycling, making them promising candidates for next generation DEFCs.

\section{Experimental}

\section{Reagents}

Platinum(II) acetylacetonate $\left(\mathrm{Pt}(\mathrm{acac})_{2}, 97 \%\right)$, tin(II) chloride pentahydrate $\left(\mathrm{SnCl}_{2} \cdot 5 \mathrm{H}_{2} \mathrm{O}\right.$, $95 \%$ ), oleylamine (OAm, $70 \%)$, oleic acid (OA, $90 \%)$ and tungsten hexacarbonyl $\left(\mathrm{W}(\mathrm{CO})_{6}\right.$, $99.99 \%$ ) were purchased from Sigma-Aldrich. Acetic acid (HOAc, $96 \%$ ) was obtained from Merck. Ethanol and acetone (Reag. Ph. Eur) were purchased from Panreac, and n-hexane (96\%) from Scharlau. 


\section{Catalyst preparation}

Pt-Sn cubic nanoparticles were prepared by using a method similar to that described by Zhang et al. $^{23} \cdot 0.032 \mathrm{mmol}$ of $\mathrm{Pt}(\mathrm{acac})_{2}, 8.0 \mathrm{~mL}$ of OAm and $2.0 \mathrm{~mL}$ of OA were added to a threeneck flask equipped with a condenser. The solution was heated to $130^{\circ} \mathrm{C}$ with mild stirring under an Ar atmosphere. At this temperature, $\mathrm{W}(\mathrm{CO})_{6}(0.108 \mathrm{mmol})$ was rapidly added to the reaction mixture, and the Ar flow was turned off at the same time. Subsequently, a solution of the $\mathrm{Sn}$ precursor, prepared by dissolving $0.032 \mathrm{mmol}$ of $\mathrm{SnCl}_{2} 5 \mathrm{H}_{2} \mathrm{O}$ in $4.0 \mathrm{~mL}$ of OAm and $1.0 \mathrm{~mL}$ of $\mathrm{OA}$, was slowly injected into the flask, and the temperature raised to $230{ }^{\circ} \mathrm{C}$ and kept at this value for $30 \mathrm{~min}$. Once the reaction was allowed to cool down, the resulting Pt-Sn nanocubes were washed twice with a mixture of hexane/ethanol $(2: 1)$ and finally dispersed in hexane. The suspension of Pt-Sn nanocubes in hexane was added to a solution containing the appropriate amount of carbon Vulcan XC-72R (to obtain a metal loading of $20 \mathrm{wt}$. \%), in hexane using a simple impregnation method, which consisted of intermittent stirring and ultrasonicating the mixture for $3 \mathrm{~h}$, and ageing overnight. The suspended Pt-Sn/C catalyst in hexane was precipitated by adding ethanol and further centrifugation. The resulting solid was dispersed in acetic acid and heated to $60^{\circ} \mathrm{C}$ for $6 \mathrm{~h}$ under stirring. Finally, the catalyst was washed with ethanol several times, filtered and dried in an oven at $70{ }^{\circ} \mathrm{C}$ overnight.

Cubic $\mathrm{Pt} / \mathrm{C}$ and unshaped $\mathrm{Pt}-\mathrm{Sn} / \mathrm{C}$ catalysts were prepared following procedures previously described $^{8,43}$. The total metal loading was 22.4 wt. \% for cubic Pt/C, 18.1 wt. \% for Pt-Sn nanocubes and 19.1 wt. \% for unshaped Pt-Sn/C. 


\section{Physicochemical characterization}

The cubic Pt-Sn/C nanocatalyst was characterized by powder XRD using a Panalytical X'Pert diffractometer with $\mathrm{Cu}-\mathrm{K} \alpha$ radiation. Diffraction patterns were collected at $3^{\circ} \min ^{-1}$ for $2 \theta$ values between $20^{\circ}$ and $100^{\circ}$. For XPS analysis, a VG-Microtech Mutilab 3000 spectrometer with a hemispherical electron analyzer and a MgAl $\alpha$ X-ray source was employed. Sample charging was corrected by referencing the energies to the $\mathrm{C} 1 \mathrm{~s}$ peak at $284.6 \mathrm{eV}$. The total metal loading was evaluated from thermogravimetric analyses (TGA,Mettler-Toledo TGA/SDTA851 thermobalance). The TEM image presented in Figure S1 was obtained on a JEOL JEM-1400 Plus microscope working at $120 \mathrm{kV}$. STEM images presented in Figures 1, S3, S5 and S6 and EDX analysis were performed using a Tecnai F20 with a Shottky field emission gun operated at $200 \mathrm{kV}$ and equipped with an Oxford X-Max $80 \mathrm{~mm}^{2} \mathrm{X}$-ray detector. The STEM-EELS images were acquired on a FEI Titan Themis S/TEM operated at 300kV equipped with a Gatan GIF Tridiem spectrometer. Composition maps for Sn and Pt were obtained by integrating the signal from the $\mathrm{Sn} \mathrm{M}_{4,5}$ and $\mathrm{Pt} \mathrm{M}_{4,5}$ edges, respectively after background subtraction using a linear combination of power laws background fit with 1.5 pixel oversampling.

\section{Electrochemical characterization}

Electrochemical experiments were carried out in a de-areated $0.5 \mathrm{M} \mathrm{H}_{2} \mathrm{SO}_{4}(98 \%$, Merck) aqueous solution at room temperature (RT) employing a Solartron model 1280 B electrochemistry station. A high surface area carbon rod was used as counter electrode and a reversible hydrogen electrode (RHE), against which all potentials are referred to, as reference electrode. Catalyst inks were prepared by ultrasonically dispersing $2 \mathrm{mg}$ of the catalyst in 
$0.5 \mathrm{~mL}$ of ultrapure water (Millipore) and $15 \mu \mathrm{L}$ of Nafion (5 wt \%). The working electrode was prepared by dropping a $10 \mu \mathrm{L}$ aliquot of the prepared ink for Pt cubes and $5 \mu \mathrm{L}$ for Pt-Sn nanocubes onto a freshly polished glassy carbon disk electrode and drying under $\mathrm{N}_{2}$ atmosphere. For EOR experiments, ethanol (Merck p.a.) was added to the de-areated electrolyte to reach a final concentration of $1.0 \mathrm{M}$.

Cyclic voltammetry (CV) was employed over a potential range from 0.05 to $0.90 \mathrm{~V}$ at a scan rate of 50 and $20 \mathrm{mV} \mathrm{s}^{-1}$ for ECSA and EOR studies, respectively. The area under the curves between 0.05 and $0.45 \mathrm{~V}$ from the CVs of Figure 5 were integrated to calculate the ECSA by using a conversion factor of $210 \mu \mathrm{C} \mathrm{cm}^{-2} 44$.

Chronoamperometry experiments at constant potential $(0.50 \mathrm{~V})$ were carried out to estimate the steady-state activity of the catalysts for the EOR for $600 \mathrm{~s}$.

\section{Results and discussion}

A cubic morphology of Pt-Sn nanoparticles was achieved by the simultaneous use of oleylamine (OLA) and oleic acid (OA) as solvent and capping agents, and $\mathrm{W}(\mathrm{CO})_{6}$ as a reducing agent ${ }^{23}$, respectively. Figure $\mathrm{S} 1$ shows some representative transmission electron microscopy (TEM) images of the as-prepared, unsupported Pt-Sn nanoparticles, which show a predominantly cubic morphology with a homogeneous size distribution and a mean edge length of $10.6 \mathrm{~nm}$ with a standard deviation of $0.4 \mathrm{~nm}$ (Figure S2). While spherical nanoparticles were occasionally observed, they represented fewer than $10 \%$ of the total. The synthesized Pt-Sn nanocubes were supported on carbon (Vulcan XC72R) and were washed 
following an acid treatment protocol described elsewhere ${ }^{29,36}$. Bright-field (BF) and annular dark-field (ADF) scanning electron microscopy (STEM) images of the carbon-supported PtSn nanoparticles (henceforth referred to as Pt-Sn/C) displayed a good dispersion of the catalyst on the carbon support following the cleaning protocol (Figure S3). The cubic morphology was further confirmed by higher magnification BF-STEM and ADF-STEM images (Figure 1a). These images further show that the crystalline Pt-Sn cubes (with visible lattice planes) are covered by a thin, low density, amorphous layer. The X-ray diffraction (XRD) pattern, shown in Figure 1b, displayed the typical face-centered cubic (fcc) peaks of Pt, namely (111), (200), (220), (311) and (222), and the graphitic reflection plane of the carbon black support (002) at $2 \theta=24.5^{\circ}$. The peak positions in the XRD pattern were shifted to lower angles when compared with $\mathrm{Pt} / \mathrm{C}$, consistent with the size difference between $\mathrm{Pt}$ and Sn and indicative of the fact that the Sn atoms have been incorporated into the fcc Pt structure to form an alloy. The surface chemical composition of the nanoparticles was also investigated by X-ray photoelectron spectroscopy (XPS).
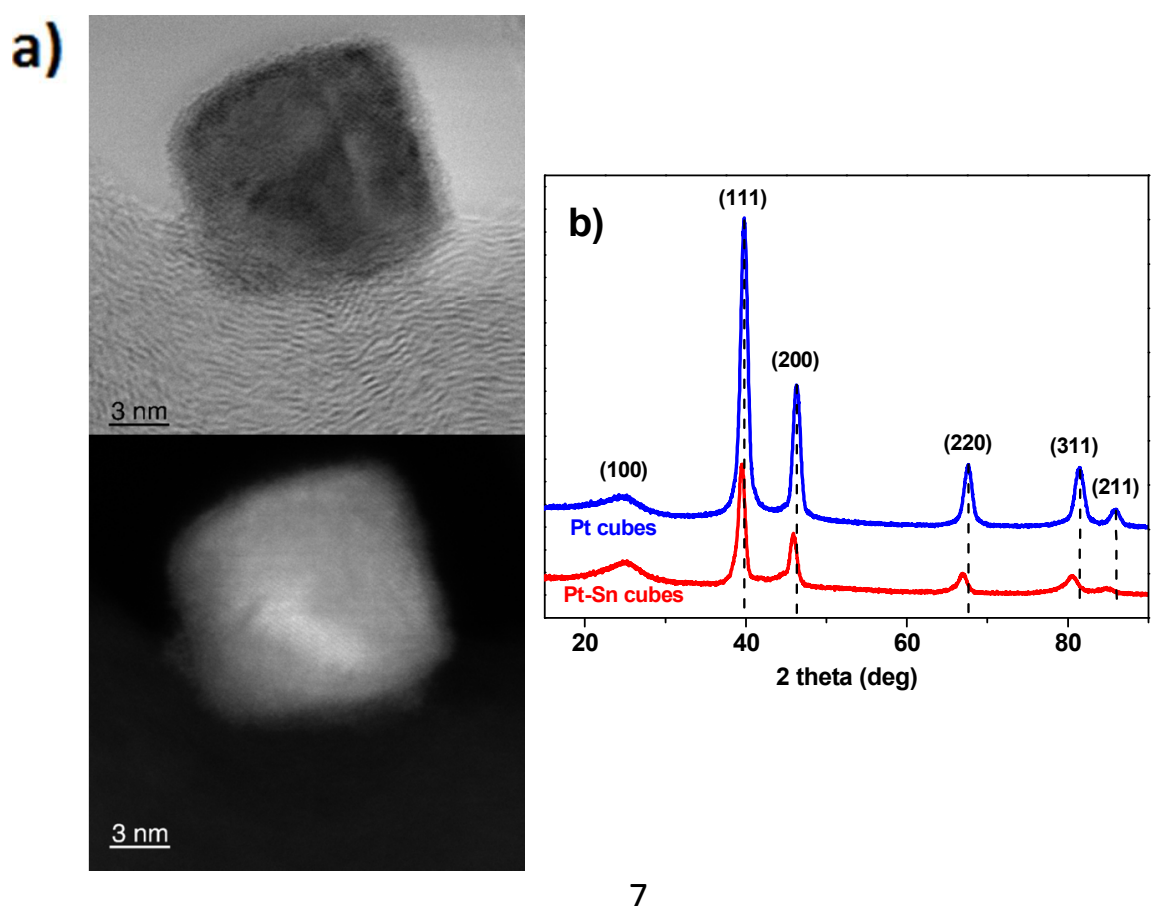
Figure 1. a) BF-STEM (top) and ADF-STEM (bottom) images of a carbon-supported Pt-Sn nanocube. b) XRD patterns of Pt and Pt-Sn nanocubes.

Figure 2 shows XPS spectra of Pt 4f (Figure 2a), deconvoluted into three peaks attributed to Pt (0), Pt (II) and Pt (IV) species located at 70.4, 71.1 and $71.9 \mathrm{eV}$, respectively, and the Sn 3d (Figure 2b) spectra, deconvoluted into two different peaks assigned to $\mathrm{Sn}(0)$ at $485.0 \mathrm{eV}$ and $\mathrm{Sn}(\mathrm{II} / \mathrm{IV})$ at $486.4 \mathrm{eV}$. As can be seen, Pt is predominantly in its reduced state (71 wt.\% as Pt (0)) whereas only 20 wt.\% and 9 wt.\% of Pt (II) and Pt (IV) were found, respectively. In stark contrast, $\mathrm{Sn}$ is mostly oxidized on the surface of the catalyst (79 wt.\% Sn (II/IV)) with only a 21 wt.\% of Sn (0) having been observed. Finally, a Pt-Sn atomic ratio of 24:76 was calculated by XPS, indicating that the amount of $\mathrm{Sn}$ is three times higher than the amount of Pt on the surface of the Pt-Sn nanocubes. This suggests that the thin, low density layer visible on the exterior of the Pt-Sn cube in Figure 1a is primarily composed of Sn oxide.
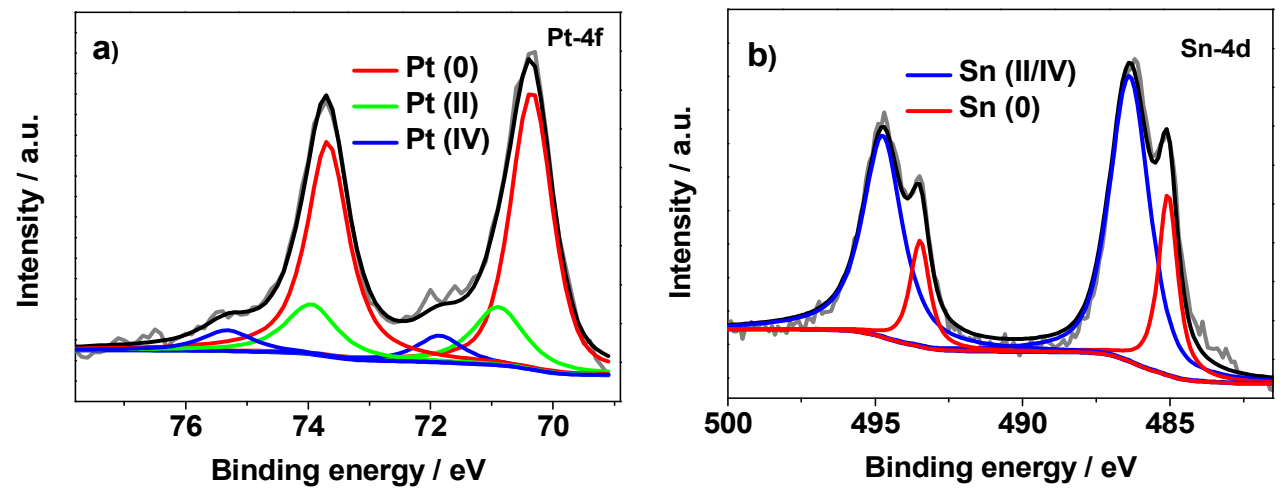

Figure 2. a) $\mathrm{Pt}_{4 \mathrm{f}}$ and b) $\mathrm{Sn}_{3 \mathrm{~d}}$ deconvoluted XPS spectra of carbon supported Pt-Sn nanocubes. 
In order to determine the distribution of $\mathrm{Pt}$ and $\mathrm{Sn}$ within the cubic nanoparticles, we performed STEM electron energy loss spectroscopy (EELS) to generate elemental composition maps. Figure 3 shows Pt and Sn EELS composition maps with a simultaneous ADF image of three Pt-Sn nanoparticles, including two cubic nanoparticles and a spherical one. The composition maps indicate that each cubic Pt-Sn nanoparticle contains a Pt-rich core surrounded by a Sn-rich shell that is approximately 2-3 nm thick. The spherical nanoparticles are Sn-rich and uniform in composition. This observation of a Sn-rich shell on the cubes is in agreement with XPS analysis, where a higher content of Sn was found at the surface of the particles. EELS maps of Pt-Sn nanoparticles oriented near the (111) direction (Figure S4) also show that the Sn-rich shell appears to be uniform across the cube, with no preference for edges, corners or faces. Energy dispersive X-ray (EDX) analysis was also employed to quantify the atomic composition of the Pt-Sn particles. The overall average composition of the catalyst was determined to be approximately 56 at.\% Pt and 44 at.\% Sn. Composition measurements on several individual particles indicated that cubic particles were 60 at. $\% \mathrm{Pt}$ and 40 at.\% Sn on average, while the less-common spherical particles were 36 at.\% Pt and 64 at.\% Sn. Line-scan measurements on cubic particles indicated that their Sn-rich shells had a typical composition of 44 at.\% $\mathrm{Pt}$ and 56 at.\% Sn near the particle surfaces, while their cores were enriched in platinum. 


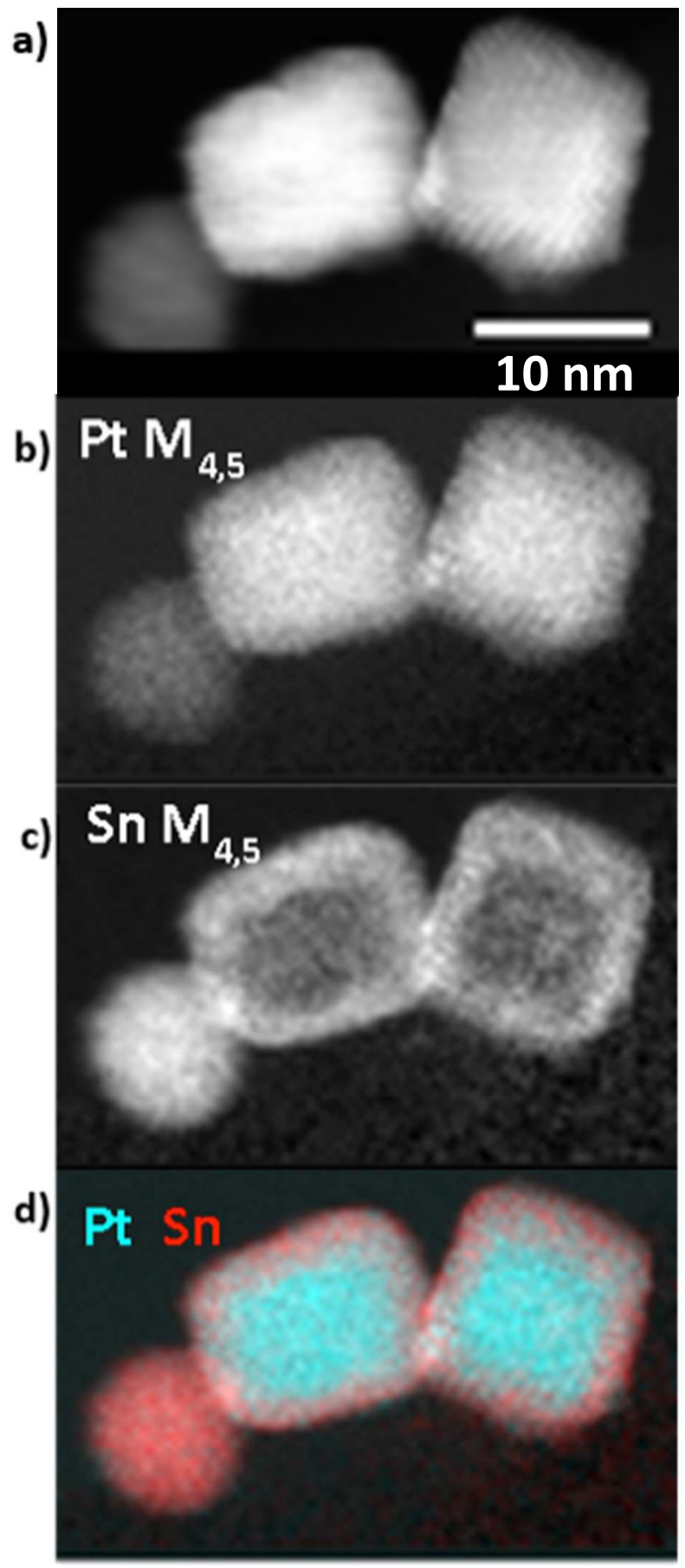

Figure 3. a) ADF-STEM image of Pt-Sn nanoparticles, b) EELS maps of Pt, c) Sn, (d) and the composite Pt-Sn map with Sn in red and Pt in cyan. 
It is generally accepted that for bimetallic Pt-based catalysts, the onset of EOR usually takes place at electrode potentials where the less noble metal is leached from the surface of the bimetallic alloy. In addition, it has been previously shown that potential cycling, especially to high potentials, can give rise to severe changes in the surface structure of shape-controlled $\mathrm{Pt}$ nanocatalysts ${ }^{44}$. For those reasons, the chemical microstructural stability and durability of the Pt-Sn cubes were evaluated by STEM imaging and EELS elemental mapping after potential cycling. The cycling protocol consisted of sweeping the electrode potential between 0.05 and $0.90 \mathrm{~V}$ vs RHE for 5,000 cycles in an Ar-saturated $0.5 \mathrm{M} \mathrm{H}_{2} \mathrm{SO}_{4}$ solution at a scan rate of a $100 \mathrm{mV} \mathrm{s}^{-1}$. The same protocol was applied to carbon supported $\mathrm{Pt}$ nanocubes $(\mathrm{Pt} / \mathrm{C})$ with a mean particle edge length of about $8.2 \mathrm{~nm}$ and a standard deviation of $1.6 \mathrm{~nm}$, obtained using the same synthetic procedure ${ }^{43,45}$. An ADF-STEM image of a collection of such particles prior to potential cycling is shown in Figure S5. STEM images of both samples were acquired before and after cycling to identify changes in the morphology and dispersion of the nanoparticles after the removal of the nanoparticles by dipping the electrode into a vial containing a high purity isopropanol solution without any sonicate process. Imaging of the PtSn cubes (Figure S6a) showed that, after 5,000 cycles, the particles maintained their cubic morphology as well as good dispersion on the carbon support, while the Pt cubes (Figure S6b), although they preserved their cubic morphology, suffered severe agglomeration after the cycling test. The improved stability of the Pt-Sn nanoparticle dispersion may be attributed, at least in part, to a higher affinity of $\mathrm{Sn}$ for the carbon support relative to $\mathrm{Pt}$, which leads to the preservation of the good dispersion of the PtSn nanoparticles after potential cycling. EELS elemental mapping (Figure 4a) and line-scans compositions, extracted from the Pt and $\mathrm{Sn}$ maps across the region indicated by the yellow arrow (Figure 4b), of cubic Pt-Sn 
nanoparticles, before and after potential cycling, show that $\mathrm{Sn}$ is leached from the catalyst surface, forming a Pt skin layer approximately $0.5 \mathrm{~nm}$ thick, as has been observed for other Pt alloy catalysts in acidic media. The resulting structure formed is Pt-rich $\mathrm{core} / \mathrm{Sn}-$ rich subsurface $/ \mathrm{Pt}_{\text {skin }}$ which is schematically depicted by models in Figure 4c.
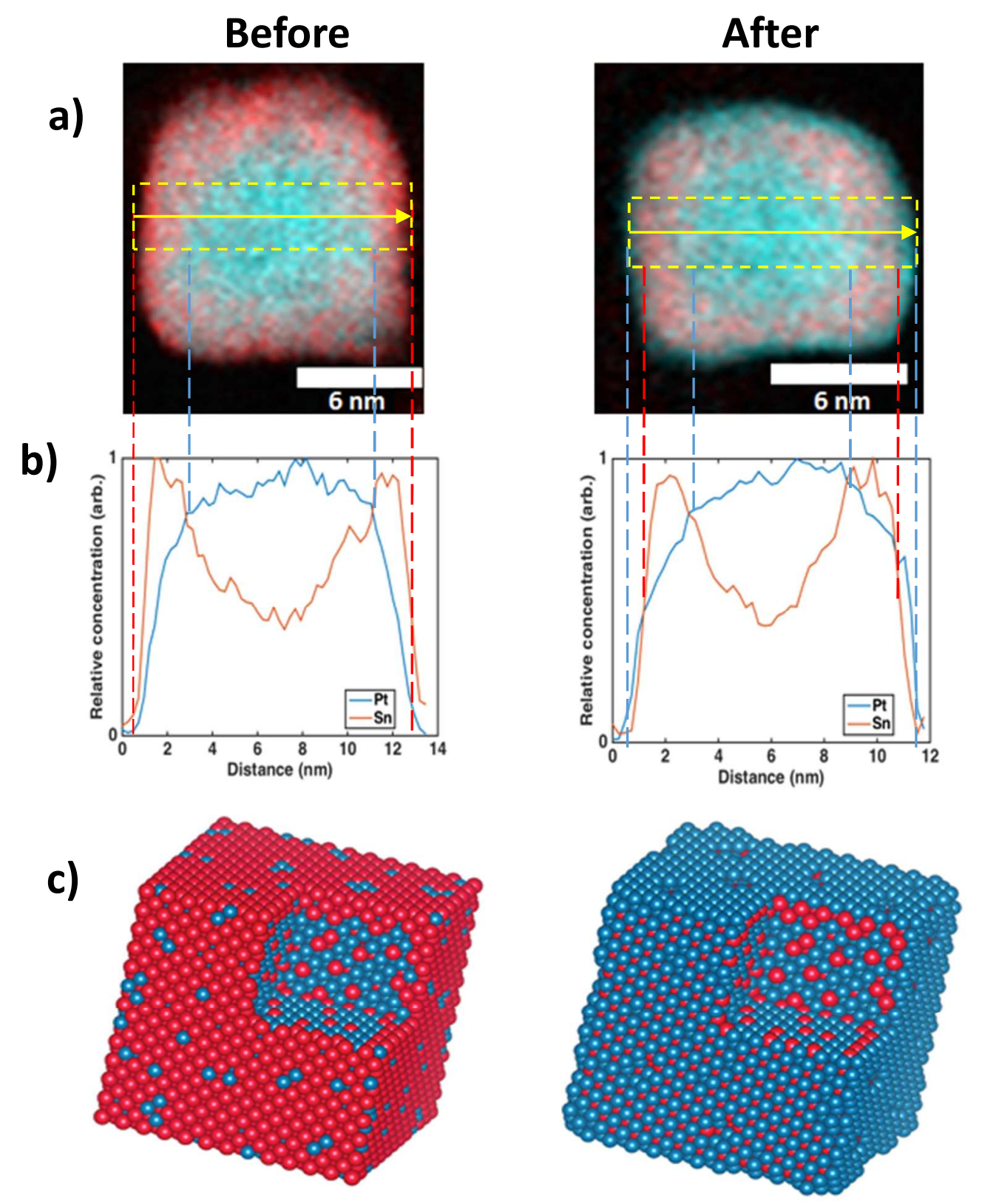

Figure 4. a) STEM-EELS composite images with $\mathrm{Sn}$ in red and Pt in cyan. b) Cross-sectional composition line profiles from EELS maps for Pt and Sn recorded across the region indicated 
by the yellow arrow in (a). c) Schematic 3D representation of a Pt-Sn cubic nanoparticle before and after subjecting the sample to potential cycling between $0.05 \mathrm{~V}$ and $0.90 \mathrm{~V}$ in 0.5 $\mathrm{M} \mathrm{H}_{2} \mathrm{SO}_{4}$ electrolyte at $100 \mathrm{mV} \mathrm{s}^{-1}$.

Cyclic voltammetry was also employed to monitor surface structure changes induced by the potential cycling. The voltammetric profiles of Pt-Sn cubic nanoparticles in sulfuric acid after 1, 1,000, 2,000, 3,000, 4,000 and 5,000 cycles are shown in Figure 5a. As can be seen, no reversible nor well-defined Pt hydrogen adsorption/desorption peaks can be observed in the first cycle since the Sn-rich shell and oxide layer cover the Pt active sites. However, the initial voltammetric profile evolved to the characteristic response of pure $\mathrm{Pt} / \mathrm{C}$, with clearly observed peaks at $0.14 \mathrm{~V}$ and $0.26 \mathrm{~V}$ emerging with continued potential cycling. On the other hand, at potentials above $0.5 \mathrm{~V}$ (where $\mathrm{OH}$ adsorption/desorption and oxide formation occurs) the current density drops with increasing number of cycles. These results are in good agreement with dissolution of the non-noble metal $(\mathrm{Sn})$ from the surface of the nanoparticles to form a $\mathrm{Pt}$ skin, as observed by STEM-EELS (Figure 4). It is worth noting that even after 5,000 potential cycles, the Pt-Sn/C displayed the characteristic voltammetric response of cubic nanoparticles, namely a peak at $0.27 \mathrm{~V}$ and a feature centered at $0.37 \mathrm{~V}$, associated with hydrogen adsorption/desorption on (100) steps and terrace borders sites, and long (100) domains, respectively ${ }^{46}$. This suggests that the Pt-Sn nanoparticles not only maintain their cubic morphology, but also their preferential (100) surface structure after the potential cycling stability test. For comparison, the stability of cubic $\mathrm{Pt} / \mathrm{C}$ nanoparticles was also tested by cyclic voltammetry (Figure 5b). The voltammetric profile shows well-defined hydrogen adsorption-desorption peaks from the initial cycle, with a profile characteristic of Pt surfaces 
with predominantly (100) facets, as described above. The $\mathrm{Pt} / \mathrm{C}$ maintains a characteristic cubic profile after extended cycling, although the peaks at +0.26 and +0.37 diminish in amplitude more rapidly than the peak at $+0.14 \mathrm{~V}$, and the corresponding features for $\mathrm{PtSn} / \mathrm{C}$, suggesting a loss of (100) surface area on the Pt/C cubes. Such a loss could be caused by reshaping of the particles (possibly/likely as a result of the incipient surface oxidation at potentials near $0.9 \mathrm{~V}$ ) or by aggregation of the Pt cubes in such a way that the cubes stick "face-to-face" blocking the (100) surfaces, thus lowering their (100) surface area.
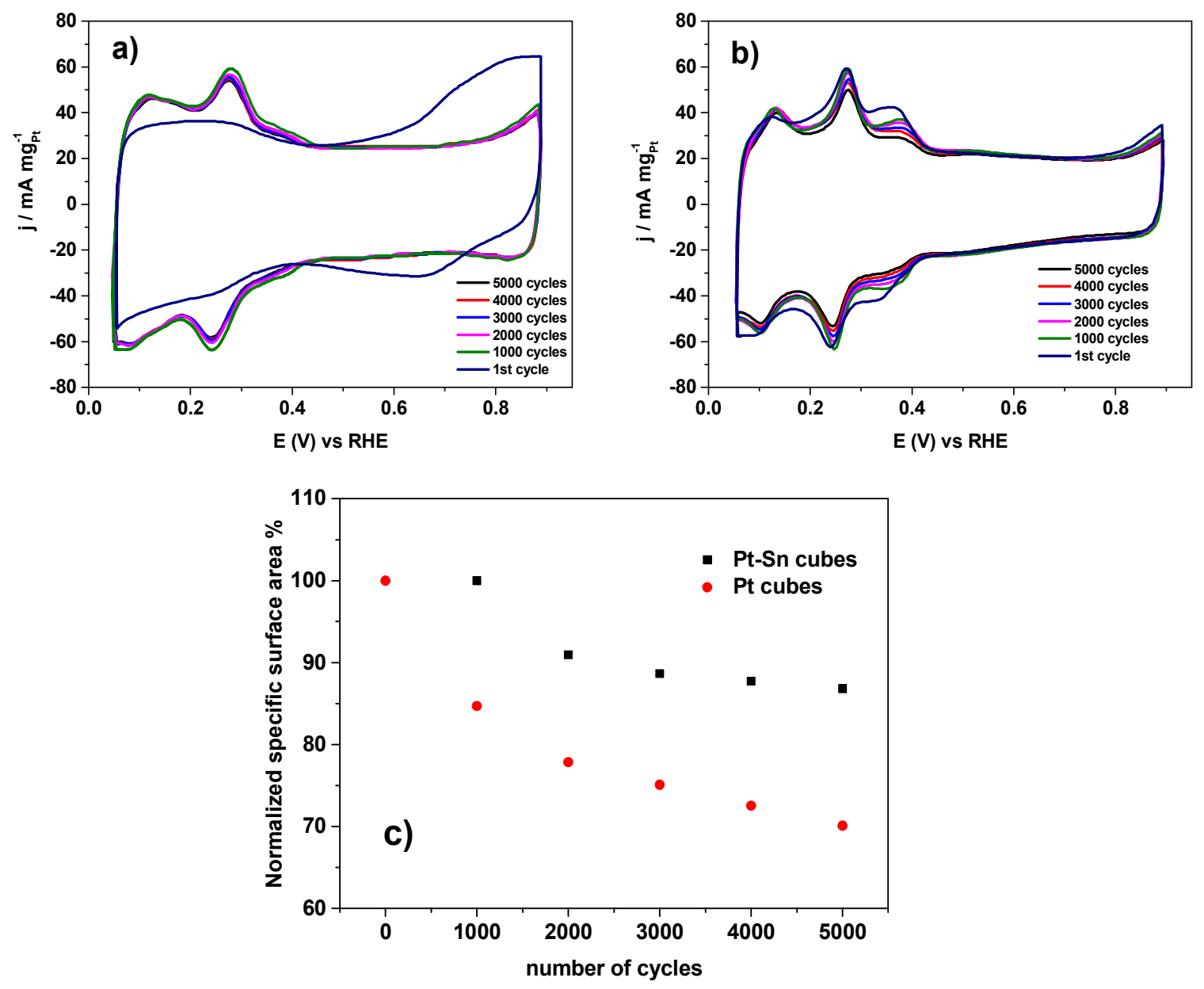

Figure 5. Voltammetric profiles of a) Pt-Sn cubes and b) Pt cubes nanoparticles in an Arpurged $0.5 \mathrm{M} \mathrm{H}_{2} \mathrm{SO}_{4}$ solution after various numbers of potential cycles, as indicated, at a scan 
rate of $100 \mathrm{mV} \mathrm{s}^{-1}$. c) \% Normalized specific surface area as a function of the number of voltammetric cycles for Pt-Sn (ם) and $\mathrm{Pt}(\bullet)$ catalysts.

Figure 5c shows the specific surface area, after a given number of potential cycles, for cubic $\mathrm{Pt}-\mathrm{Sn} / \mathrm{C}$ and $\mathrm{Pt} / \mathrm{C}$ samples, calculated from the charge involved in the adsorption of hydrogen (after double-layer subtraction) between 0.05 and $0.45 \mathrm{~V}^{43}$ and normalized by the maximum Pt specific surface area values $\left(31 \mathrm{~m}^{2} \mathrm{~g}_{\mathrm{Pt}}{ }^{-1}\right.$ for Pt cubes after 1 cycle and $32 \mathrm{~m}^{2} \mathrm{~g}_{\mathrm{Pt}}{ }^{-1}$ for Pt-Sn cubes after 1000 cycles). It can be seen that the specific surface area for Pt nanocubes decreased more rapidly, with potential cycling, than for the Pt-Sn nanocubes, with losses of $30 \%\left(21.7 \mathrm{~m}^{2} \mathrm{~g}_{\mathrm{Pt}}{ }^{-1}\right)$ and $15 \%\left(27.2 \mathrm{~m}^{2} \mathrm{~g}_{\mathrm{Pt}}{ }^{-1}\right)$ after 5,000 cycles, respectively.

The electrocatalytic activity of the cubic Pt-Sn/C catalyst, towards ethanol electrooxidation, was evaluated in acidic electrolyte and compared to that of the cubic $\mathrm{Pt} / \mathrm{C}$ sample as well as with that of an unshaped Pt-Sn/C nanocatalyst, with a mean diameter of about $3.1 \mathrm{~nm}$, with a $\mathrm{Pt}: \mathrm{Sn}$ atomic ratio of $1: 1$, used in previous work $^{8,9}$. Figure 6 a shows the EOR profiles for the cubic Pt-Sn/C nanocatalyst, before and after a pretreatment in $0.5 \mathrm{M} \mathrm{H}_{2} \mathrm{SO}_{4}$ solution during 5,000 potential cycles. The initial current is low, suggesting that under these conditions, the significant amount of $\mathrm{Sn}$ in the $\mathrm{Sn}$-rich shell hinders the oxidation of ethanol on Pt atoms (which are known to be the active sites). In addition, the dissolution of the Sn shell after 5,000 cycles in acid media leads to more exposed Pt atoms with low coordination number available to react with ethanol. In addition, the EOR profile on the unmodified glassy carbon was also included in the supporting information for comparison (Figure S7), where can be observed that the bare glassy carbon is inactive for the EOR. The electrocatalytic activity of the cycled Pt-Sn nanocubes was compared to that exhibited by the cubic $\mathrm{Pt} / \mathrm{C}$ and unshaped $\mathrm{Pt}-\mathrm{Sn} / \mathrm{C}^{8,9}$ 
catalysts. The EOR voltammetric profiles for the three samples are shown in Figure 6b. The voltammetric profiles and electrocatalytic activity towards the EOR of cubic $\mathrm{Pt} / \mathrm{C}$ and unshaped Pt-Sn/C catalysts after 5,000 cycles were not obtained due to the lower initial activity (in the first cycle) of these catalysts, compared with the activity of Pt-Sn nanocubes after the stability test. Current densities (j) were normalized to the electroactive surface area (ECSA) to obtain the specific activities (current densities in $\mathrm{mA} \mathrm{cm}{ }^{-2}$ ) of the different catalysts, and as can be observed, the cubic Pt-Sn/C sample exhibited the highest electrocatalytic activity among the three catalysts studied. The superior EOR catalytic performance and catalyst stability of the Pt-Sn nanocubes was further confirmed by potentiostatic chronoamperometry experiments at a potential of $+0.50 \mathrm{~V}$ (Figure 6c). 

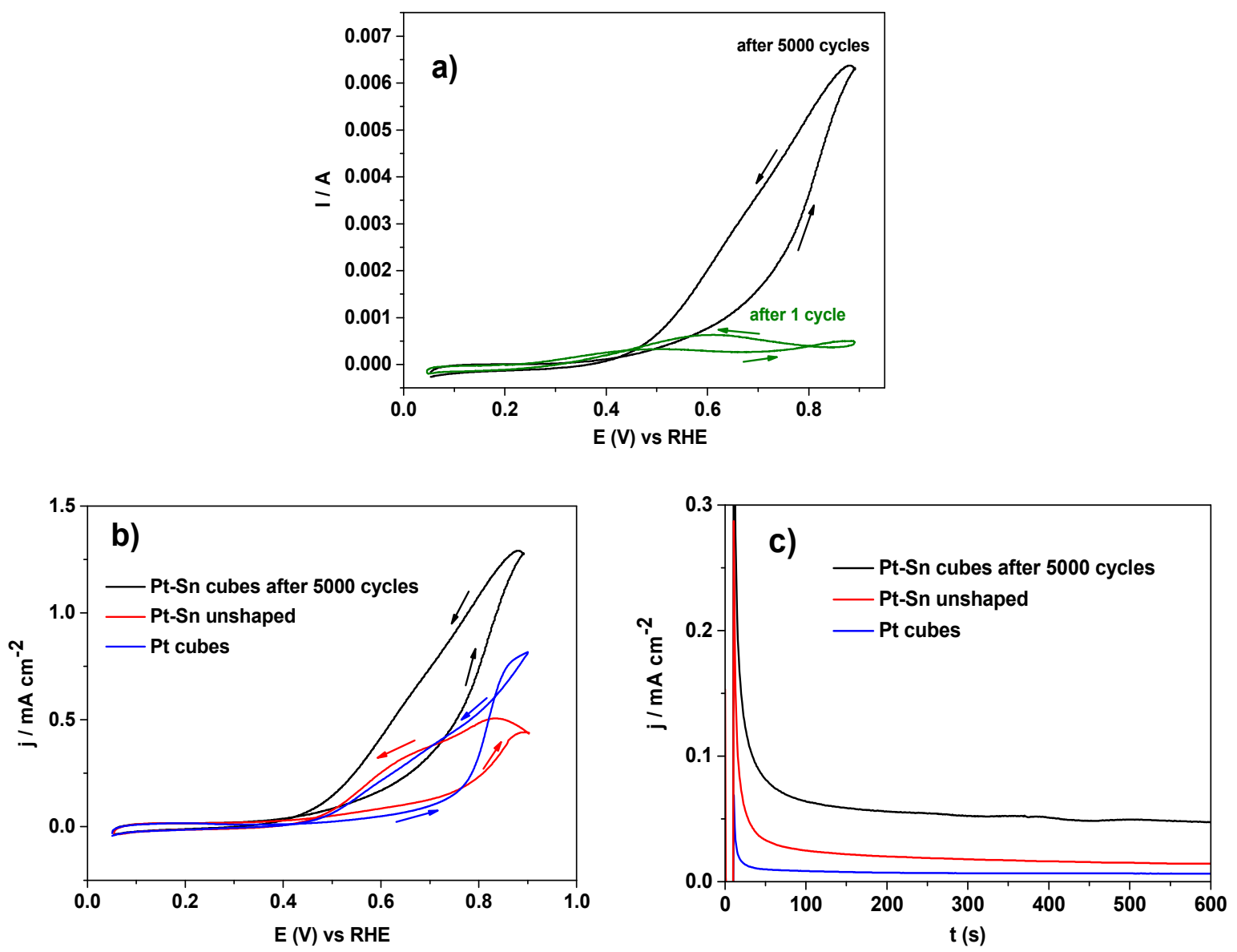

Figure 6. a) Cyclic voltammetric profiles for the EOR on Pt-Sn nano cubes after 1 and 5,000 cycles at a scan rate of $20 \mathrm{mV} \mathrm{s}^{-1}$. b) Comparison of EOR curves at a scan rate of $20 \mathrm{mVs}^{-1}$ and c) current transients at $0.50 \mathrm{~V}$ (from an initial potential of $+0.05 \mathrm{~V}$ ) of the activated Pt-Sn nanocubes (black), unshaped Pt-Sn nanoparticles (red) and Pt-cubic nanoparticles (blue) in Ar-purged $0.5 \mathrm{M} \mathrm{H}_{2} \mathrm{SO}_{4}+1 \mathrm{M} \mathrm{EtOH}$ solution.

The transients were carried out by stepping the potential from a value where ethanol oxidation was negligible $\left(E_{i}=0.05 \mathrm{~V}\right.$ vs RHE), to $0.50 \mathrm{~V}$ (typical potential for fuel cell operation), and holding the potential at this latter value for $600 \mathrm{~s}$. The behavior typical for Pt-based electrodes was found in all cases, namely, a sharp current decay at short times, subsequently attaining a stationary value. The current decay depends on the adsorption, on Pt, of strongly adsorbed CO 
$\left(\mathrm{CO}_{\mathrm{ad}}\right)$ and $\mathrm{CH}_{\mathrm{x}, \mathrm{ad}}$ formed during the oxidation of ethanol, and which require high potentials to be oxidized and, thus, removed from the surface ${ }^{4,5}$. The cycled cubic Pt-Sn/C nanoparticles exhibited outstanding durability towards ethanol oxidation, with steady-state currents about three times higher than those exhibited by unshaped Pt-Sn nanoparticles and six times higher than Pt nanocubes.

We ascribe the exceptional activity of the cycled Pt-Sn nanocubes to two main factors. On the one hand, the catalyst has a high density of $\operatorname{Pt}(100)$ surface sites, which favor the cleavage of the $\mathrm{C}-\mathrm{C}$ bond of the ethanol molecule ${ }^{17}$. In addition, the PtSn interior of the nanocubes can exert both an electronic effect as well as a lattice strain effect, both of which are well known to enhance electrocatalytic activity. It is also possible that the presence of Sn enhances the oxidation of strongly adsorbed intermediate species such as $\mathrm{CO}$ and other reaction intermediates. In fact, a significant catalytic enhancement effect for the EOR was recently observed by the modification of $\mathrm{Pt}$ nanocubes with $\mathrm{Sn}$ adatoms ${ }^{47}$. In that case, the enhancement was ascribed to a faster removal of $\mathrm{CO}$ from the surface of Pt during the reaction. While that is possible in our case, the EELS elemental mapping after potential cycling indicated that the outermost layer of the nanocubes was essentially pure platinum, which would argue against such an effect in the present case.

\section{Conclusions}

In summary, in this work we present a novel nanostructured electrocatalyst for the EOR consisting of Pt-Sn nanocubes having a Pt-rich core, a Sn-rich subsurface layer and a Pt-skin

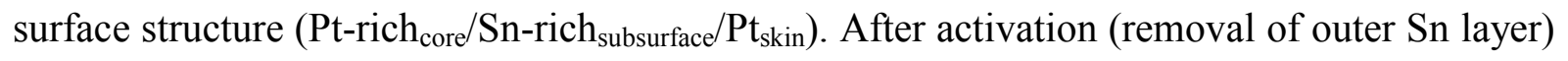


this material exhibits exceptional electrocatalytic performance, with activities three times higher than unshaped Pt-Sn catalysts and six times higher than cubic Pt nanoparticles. Moreover, this electrocatalyst not only shows superior EOR catalytic performance, but also greater durability with lower specific surface area loss after 5,000 cycles. Our study provides a promising electrocatalyst for DEFCs, in particular, and alcohol based fuel cells, in general.

\section{Acknowledgments}

This work has been supported by Fundación Cajacanarias (project BIOGRAF), the Ministry of Economy and Competitiveness (MINECO) through the projects CTQ2011-28913-C02-02 and ENE2014-52158-C2-2-R (co-funded by FEDER) and the. The authors acknowledge the SEGAI services of Universidad de La Laguna for important technical assistance and R.R also thanks the funding received from MINECO (EEBB-I-16-11762) to carry out a predoctoral stay in a foreign R\&D center. E.P. acknowledges support from an electron microscopy facilities supported by the NSF MRSEC program (DMR 1120296) and an NSF MRI grant (DMR 1429155).J.S.G. acknowledges financial support from VITC (Vicerrectorado de Investigación y Transferencia de Conocimiento) of the University of Alicante. 


\section{References}

(1) Antolini, E. J. Power Sources 2007, 170, 1.

(2) Lamy, C.; Belgsir, E. M.; Léger, J. M. J. Appl. Electrochem. 2001, 31, 799.

(3) De Souza, J.; Queiroz, S.; Bergamaski, K.; Gonzalez, E.; Nart, F. J. Phys. Chem. B 2002, 106, 9825.

(4) Pastor, E.; Iwasita, T. Electrochim. acta 1994, 39, 547.

(5) Iwasita, T.; Pastor, E. Electrochim. Acta 1994, 39, 531.

(6) Ianniello, R.; Schmidt, V. M.; Rodríguez, J. L.; Pastor, E. J. Electroanal. Chem. 1999, $471,167$.

(7) Dong, L.; Gari, R. R. S.; Li, Z.; Craig, M. M.; Hou, S. Carbon 2010, 48, 781.

(8) Rizo, R.; Sebastián, D.; Lázaro, M. J.; Pastor, E. Appl. Catal. B-Environ. 2017, 200, 246.

(9) Rizo, R.; Lázaro, M. J.; Pastor, E.; García, G. Molecules 2016, 21, 1225.

(10) Du, W.; Yang, G.; Wong, E.; Deskins, N. A.; Frenkel, A. I.; Su, D.; Teng, X. J. Am. Chem. Soc. 2014, 136, 10862.

(11) Erini, N., Loukrakpam, Rameshwori; Petkov, V.; Baranova, E. A.; Yang, R.; Teschner, D.; Huang, Y.; Brankovic, S. R.; Strasser, P. ACS Catal. 2014, 4, 1859.

(12) Erini, N.; Rudi, S.; Beermann, V.; Krause, P.; Yang, R.; Huang, Y.; Strasser, P. ChemElectroChem 2015, 2, 903.

(13) Moraes, T. S.; Neto, R. C. R.; Ribeiro, M. C.; Mattos, L. V.; Kourtelesis, M.; Ladas, S.; Verykios, X.; Noronha, F. B. Appl. Catal. B-Environ. 2016, 181, 754. 
(14) Wang, H.; Jiang, K.; Chen, Q.; Xie, Z.; Cai, W.-B. Chem. Comm. 2016, 52, 374.

(15) Li, H.; Wu, H.; Zhai, Y.; Xu, X.; Jin, Y. ACS Catal. 2013, 3, 2045.

(16) Lai, S. C.; Koper, M. T. Phys. Chem. Chem. Phys. 2009, 11, 10446.

(17) Colmati, F.; Tremiliosi-Filho, G.; Gonzalez, E. R.; Berna, A.; Herrero, E.; Feliu, J. M. Phys. Chem. Chem. Phys. 2009, 11, 9114.

(18) Busó-Rogero, C.; Herrero, E.; Feliu, J. M. ChemPhysChem 2014, 15, 2019.

(19) Abd-El-Latif, A.; Mostafa, E.; Huxter, S.; Attard, G.; Baltruschat, H. Electrochim. Acta 2010, 55, 7951 .

(20) El-Shafei, A. A.; Eiswirth, M. Surf. Sci. 2010, 604, 862.

(21) Del Colle, V.; Souza-Garcia, J.; Tremiliosi-Filho, G.; Herrero, E.; Feliu, J. M. Phys. Chem. Chem. Phys. 2011, 13, 12163.

(22) Rizo, R.; Lázaro, M. J.; Pastor, E.; Koper, M. ChemElectroChem 2016, 3, 2196

(23) Zhang, J.; Fang, J. J. Am. Chem. Soc. 2009, 131, 18543.

(24) Wu, J.; Gross, A.; Yang, H. Nano letters 2011, 11, 798.

(25) Choi, S.-I.; Choi, R.; Han, S. W.; Park, J. T. Chem. Comm. 2010, 46, 4950.

(26) Chou, S.-W.; Zhu, C.-L.; Neeleshwar, S.; Chen, C.-L.; Chen, Y.-Y.; Chen, C.-C. Chem. Mater. 2009, 21, 4955.

(27) Xu, D.; Liu, Z.; Yang, H.; Liu, Q.; Zhang, J.; Fang, J.; Zou, S.; Sun, K. Angew. Chem. Int. Edit. 2009, 48, 4217.

(28) Zhang, J.; Yang, H.; Fang, J.; Zou, S. Nano letters 2010, 10, 638. 
(29) Choi, S.-I.; Xie, S.; Shao, M.; Odell, J. H.; Lu, N.; Peng, H.-C.; Protsailo, L.; Guerrero, S.; Park, J.; Xia, X. Nano letters 2013, 13, 3420.

(30) Cui, C.; Gan, L.; Li, H.-H.; Yu, S.-H.; Heggen, M.; Strasser, P. Nano letters 2012, 12, 5885.

(31) Cui, C.; Gan, L.; Heggen, M.; Rudi, S.; Strasser, P. Nat. mater. 2013, 12, 765.

(32) Gan, L.; Cui, C.; Heggen, M.; Dionigi, F.; Rudi, S.; Strasser, P. Science 2014, 346, 1502.

(33) Sun, X.; Jiang, K.; Zhang, N.; Guo, S.; Huang, X. ACS nano 2015, 9, 7634.

(34) Huaman, J. L. C.; Fukao, S.; Shinoda, K.; Jeyadevan, B. CrystEngComm 2011, 13, 3364.

(35) Wu, J.; Zhang, J.; Peng, Z.; Yang, S.; Wagner, F. T.; Yang, H. J. Am. Chem. Soc. 2010, 132, 4984.

(36) Arán-Ais, R. M.; Solla-Gullón, J.; Gocyla, M.; Heggen, M.; Dunin-Borkowski, R. E.; Strasser, P.; Herrero, E.; Feliu, J. M. Nano Energy 2016, 27, 390.

(37) Arán-Ais, R. M.; Dionigi, F.; Merzdorf, T.; Gocyla, M.; Heggen, M.; DuninBorkowski, R. E.; Gliech, M.; Solla-Gullón, J.; Herrero, E.; Feliu, J. M. Nano letters 2015, $15,7473$.

(38) Chen, Q.; Yang, Y.; Cao, Z.; Kuang, Q.; Du, G.; Jiang, Y.; Xie, Z.; Zheng, L. Angew. Chem. 2016, $128,9167$.

(39) Busó-Rogero, C.; Grozovski, V.; Vidal-Iglesias, F. J.; Solla-Gullón, J.; Herrero, E.; Feliu, J. M. J. Mater. Chem. A 2013, 1, 7068.

(40) Figueiredo, M. C.; Solla-Gullón, J.; Vidal-Iglesias, F. J.; Nisula, M.; Feliu, J. M.; Kallio, T. Electrochem. Comm. 2015, 55, 47. 
(41) Busó-Rogero, C.; Brimaud, S.; Solla-Gullon, J.; Vidal-Iglesias, F. J.; Herrero, E.; Behm, R. J.; Feliu, J. M. J. Electroanal. Chem. 2016, 763, 116.

(42) Wei, L.; Fan, Y.-J.; Wang, H.-H.; Tian, N.; Zhou, Z.-Y.; Sun, S.-G. Electrochim. Acta 2012, 76, 468 .

(43) Arán-Ais, R. M.; Vidal-Iglesias, F. J.; Solla-Gullón, J.; Herrero, E.; Feliu, J. M. Electroanal. 2015, 27, 945.

(44) Arán-Ais, R. M.; Yu, Y.; Hovden, R.; Solla-Gullón, J.; Herrero, E.; Feliu, J. M.; Abruña, H. D. J. Am. Chem. Soc. 2015, 137, 14992.

(45) Arán-Ais, R. M.; Vidal-Iglesias, F. J.; Farias, M. J.; Solla-Gullón, J.; Montiel, V.; Herrero, E.; Feliu, J. M. J. Electroanal. Chem. 2016, 793, 126.

(46) Vidal-Iglesias, F.; Solla-Gullón, J.; Montiel, V.; Feliu, J.; Aldaz, A. J. Power Sources 2007, 171, 448 .

(47) Busó-Rogero, C.; Solla-Gullón, J.; Vidal-Iglesias, F. J.; Herrero, E.; Feliu, J. M. Electrochimica Acta 2016, 196, 270. 


\title{
Pt-richcore/Sn-richsubsurface/Ptskin nanocubes as highly active and stable electrocatalysts for the ethanol oxidation reaction
}

\author{
Rubén Rizo ${ }^{1 *}$, Rosa M. Arán-Ais ${ }^{2}$, Elliot Padgett ${ }^{4}$, David A. Muller ${ }^{4}, \mathrm{M}^{\mathrm{a}}$ Jesús Lázaro $^{5}$, José \\ Solla-Gullón ${ }^{2}$, Juan M. Feliu ${ }^{2}$, Elena Pastor ${ }^{1}$, Héctor D. Abruña ${ }^{3 *}$
}

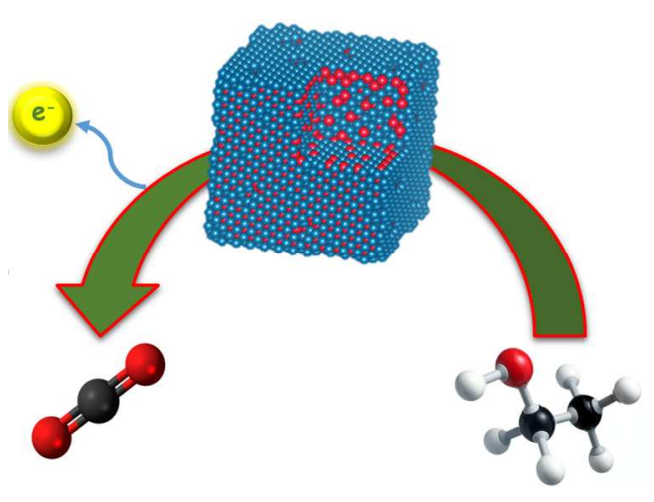

